\title{
Детство в Сибири: восприятие пространства эстонцами, пережившими советскую депортацию
}

\section{Введение}

В обыденном сознании россиян представляется, что культурная политика Эстонии основывается на негативной оценке своего советского прошлого и противодействии России как правопреемницы СССР. Вместе с тем полностью отсутствуют научные труды, как-либо анализирующих её с исследовательской точки зрения, без ангажированных оценок. Поэтому подобные выводы строятся на сообщениях из средств массовой информации, которые не являются специалистами в данной области.

Действительно, политика памяти современной Эстонии опирается на такие исторические фракты, которые оцениваются как преступления против человечности, и, напротив, забываются фракты, свидетельствующие о помощи прибалтийским странам со стороны верхушки СССР, например, индустриализация стран Прибалтики, что автоматически в эстонском обществе смешивается и со всем образом России в целом. Однако, при отрицательном отношении к правительству Советского союза, российско-эстонские отношения переживают заметное потепление ввиду соседской близости и экономической выгоды. И культурная политика Эстонии не имеет однонаправленное движение, о чём свидетельствует лихуласский кризис 2004 г.

Особое внимание в истории Эстонии уделяется депортации эстонцев советским правительством в Сибирь, наиболее крупная волна которой прошла в 1949 г. Независимо от реальных или скрытых целей, она подаётся как главное событие, принёсшее ущерб эстонскому обществу от советского периода. Но с течением временем отношение к ней также меняется, и появляются более сложные аспекты культурного содержания политики памяти в отношении этих событий. Вместо тех, кто переживал непосредственную высылку, чьи личные судьбы ломались депортацией, на первый план выходят люди, которые родились или провели своё детство в Сибири, а значит, Сибирь для них является второй, а для кого-то и первой родиной. В данной работе представлен анализ арт-программы "Детство в Сибири", проходившей в Эстонии в 2019 г., посвящённой памяти депортации соотечественников вследствие советской операции "Прибой" 1949 г.

\section{Методология}

Данная тема лежит одновременно в нескольких научных измерениях: культурологическом, политическом и географическом. В культурологическом плане мы заходим в обширное поле memory studies, а точнее политики памяти и способах её выражения. Основным методом исследований политики памяти является анализ репрезентаций прошлого. Репрезентации являются отражением как коллективной, так и индивидуальной памяти $[11 ; 12]$. Отдельным направлением в политике памяти является исследования травм культурной памяти [1], с которой мы и имеем дело в объекте исследования. Анализ проводится как посредством селекции всей совокупности образов, циркулирующих

(С Фартышев А. Н., Раева Д. Д., 2021

ФАРТЫШЕВ Арсений Николаевич, канд. геогр. наук, доцент кафедры истории, политологии и регионоведения Иркутского государственного университета, научный сотрудник лаборатории георесурсоведения и политической географии института географии им. В.Б. Сочавы СО РАН (2. Иркутск). E-mail: fartyshev.an@gmail.com

PAEВА Диана Дмитриевна, студент Иркутского государственного университета (2. Иркутск). E-mail: raeva.diana@mail.ru 
в обществе, их семантике и интерпретации, так и преднамеренном забвении тех образов, которые утратили свою актуальность. Сосредоточившись на репрезентациях прошлого, необходимо не упустить из вида центральную роль человека в истории как создателя репрезентаций [19, с. 185]. В нашем случае репрезентантами являются люди, пережившие события 1949 г. в детском возрасте, и именно в этом есть особенность.

В политическом плане (хотя и политика памяти также кроссдисциплинарна с политологией) мы имеем дело с областью критической геополитики, поскольку в нашем контексте затрагиваются взаимоотношения двух стран, имеющих сложную историю двусторонних контактов. Критическая геополитика (или низкая геополитика) рассматривает взаимоотношения между странами не на правительственном уровне, а на уровне общества стран [9]. Для идентификации настроений на низших уровнях применяется дискурсивный анализ публичных выступлений и статей в СМИ, социологические и эксперт-опросы, количественные показатели двусторонних контактов. Критическая геополитика связана также и с географией эмоций, отражающей ментальные установки коллективного поведения [14]. Нас интересуют именно содержательный базис двусторонних отношений, выраженный в концепции культурной политики, связанный со сменой поколений непосредственных участников событий.

В географическом плане мы имеем дело с ментальной географией, то есть тем, как пространство отражается в сознании людей. Эту область исследований называют также географией образов [5; 15], метагеографией [7] или постгеографией [8]. Географическими образами сознательно и бессознательно восстанавливают картину мира человека. В трудах Замятина Д.Н. раскрывается смысл географических образов как сложный целенаправленный контекст восприятия географического пространства. И так стало возможным сознательное конструирование обобщенных макрогеографических образов, которые как бы поглощали или замещали собой реальные географические пространства [6, с. 13]. Идентификация таких образов создаёт возможности для когнитивного моделирования и картирования стран и регионов (как, например, это сделано на Черноморско-Каспийский регион [3]). Для нашего исследования важно понять, какие существуют географические образы России и Сибири, в частности, в сознании әстонцев. Поскольку географическая среда является одним из важных компонентов воспитания культурных ценностей [13], с этих позиций мы рассматриваем современную политику памяти, посвящённой депортации эстонцев как пример для понимания пространства детьми.

\section{Данные}

Кратко опишем событие памяти. В конце марта 1949 г. началась операция под названием "Прибой" - депортация жителей Эстонии, Латвии и Литвы в Сибирь. Главной целью депортации, согласно постановлению Совета министров СССР "были семьи бандитов и националистов, находящихся на нелегальном положении, убитых при вооруженных столкновениях и осужденных, легализованные бандиты, продолжающие вести вражескую работу, и их семьи, а также семьи репрессированных пособников бандитов". Офрициально под этой категорией подразумевались "лесные братья", националисты, боровшиеся за независимость прибалтийских стран. Общее количество пострадавших от мартовской депортации составляло около 21 тысячи человек. Во время десталинизации и "хрущевской оттепели" депортированные были постепенно освобождены, и к началу 1960-х гг. большинство из них вернулись в Эстонию; они оставались под надзором КГБ [4].

Период депортации 1940-х г. оказал сильное влияние на народы Прибалтики. После распада СССР Эстония, как и другие Прибалтийские государства, встали перед необходимостью построения новой гражданской идентичности, основанной на этническом фракторе в противоположность советской, которая бы отвечала параметрам заданной независимости, антироссийским устремлениям и так далее. И у Эстонии накоплен достаточно маленький опыт собственного государственного бытия, к сожалению, не оказалось других национальных героев, кроме членов полицейских батальонов, Эстонского легиона вафрфен-СС, которые сражались против Советского Союза. Именно 
поэтому их и пытаются героизировать на национальном уровне. И это и является причиной конфрликта отношений с Россией, где память о Великой Отечественной войне как об антифашистском событии является одним из основных признаков гражданской идентичности. Однако подобный конфликт потенциально возможен не только с Россией, но и с Европой. Проблема идентичности в Эстонии в результате выразилась в лихуласском кризисе 2004 г., возникшего из-за общественного возмущения сначала об установке памятника эстонцам, воевавшим на стороне фашистской Германии, затем о его сносе. Настрой настолько стал радикальным, что общественность вынудила правительство Эстонии уйти в отставку, но в итоге произошёл откат от фрашистской риторики [2, с. 114]. Также со временем Эстония и Россия вынуждены искать точки соприкосновения для эффрективного сотрудничества на экономической и политической почве, причём Эстония из-за роста международной влиятельности России вынуждена не идти на открыто недружественные акции, поэтому в последние годы депортационная повестка становится не настолько актуальной.

В 2019 г. исполнился 70-летний юбилей с описанных выше событий. Инициативная группа под руководством Марики Альвер (преподаватель этнографии Таллинской академии искусств) создала уникальный проект "Siberi lapsepõlv", что с эстонского переводится как "Детство в Сибири", посвящённое последнему поколению, пережившему эти события. Это люди, которые были депортированы в Сибирь в детстве или родились в Сибири. Группа под руководством Марики Альвер работала в Сибири два года подряд, в течение которых они запечатлели их детские пейзажи, запахи и вкусы, знакомые с детства, и друзей, оставшихся в Сибири. Этот уникальный опыт вдохновил на создание серии выставок под общим названием "Сибирское детство", проходящих на вокзалах 16 железнодорожных станций, расположенных в Эстонии, с которых начались роковые путешествия [20]. Выставки не просто отражают картины, но и включают в себя аудиальные, визуальные и ольфакторные инсталлящии. Например, на вокзале г. Хаапсалу были размещены саженцы черёмухи, в других городах предлагали выпить отвар иван-чая, во время творческих встреч воспроизводили народные песни, сочинённые во время депортации.

В рамках проекта "Сибирское детство" в Эстонии указанные 16 железнодорожных станций были переименованы названиями сибирских городов и станций, в которые были депортированы люди в 1949 г. (например, на вокзале в Тарту висела табличка "Омск", в г. Тапа - "Абакан" и т. д. $\left.{ }^{\mathbf{1}}\right)$

Проект был также поддержан эстонским национально-культурным фондом, ассоциацией "Broken Cornflower", эстонским фондом помощи репрессированным лица, Таллинским советом по культуре и др.

\section{Результаты}

Нами были собраны подробные описания всех культурных инсталляций программы "Детство в Сибири", видеоматериал, интервью участников программы, публикации в СМИ и социальных сетях касательно отношения в данной инициативе, что позволило комплексно проанализировать интерпретации прошлого в современной художественной форме: как участники программы интерпретировали свою жизнь в Сибири, какие образы запечатлены в их коллективной памяти, какие культурные коды заложены в посылах современному эстонскому обществу, которое так мало знает как о депортации, так и об этом регионе в целом, который плотно ассоциируется с негативным окрасом России, создаваемым пропагандой эстонских СМИ и властей.

Главными итогами анализа семантики арт-программы следует отметить три важных пункта. Первым является обнаружение смены осуждения и агрессии в сторону Советского Союза ностальгическими настроениями детских воспоминаний депортантов. Как отмечается в пресс-релизе арт-программы, депортация может во многих отношениях рассматриваться как насилие в отношении женщин и детей. Однако для "сибирских детей" депортация - это было то, где их жизнь началась, а не закончилась. Их образ жизни был сфор-

1 Названия были написаны кириллицей даже несмотря на национальную политику по искоренению русского языка в Эстонии. Впрочем, в некоторых муниципалитетах это вызвало общественное недовольство [18]. 
мирован не только во время отправки в Сибирь, но и во время возвращения оттуда и приспособления к жизни в Эстонии. Таким образом, сама депортация в отражении сибирских детей, не настолько травматично отразилась в их сознании, и ныне они ретранслируют такие образы, которые исключают трагичность и осуждение. Среда обитания сильнее всего влияет на картину мира человека, потому что он находится под давлением всевозможных фракторов влияния пространства и ставит свои границы на восприятие как самого себя, своей культуры, так и понимания чужой культуры. Детям легче адаптироваться в чужой культуре, нежели старшим поколениям, и потому в ретранслируемых образах мы видим типичную сибирскую культуру, пропущенную через призму индивидуального восприятия.

Второе, что было выявлено: непосредственно сам географический образ Сибири заключён в восприятии эстонцев совершенно иначе, чем образ самой России. Если Россия воспринимается как правопреемница СCCP, оправдывающая депортацию 1949 г., что воспринимается в әстонском обществе как преступление, то Сибирь, несмотря на обстоятельства, воспринимается эстонцами, и в частности людьми, которые побывали в высылке в детском возрасте, как нечто противоположное враждебности, и как вторая родина, что запечатлено в объектах и событиях, создаваемых арт-программой "Детство в Сибири". Если Советский Союз для них ассоциируется с государством, то Сибирь - с обществом, в котором они жили бок о бок, которое дружественно принимало депортантов без вытеснения чуждого элемента. Это связано с особенностями сибирского общества, которое также сформировалось в ходе различных переселенческих кампаний как насильственного, так и добровольного характера. В выставках "Горы далеко, море ещё дальше" мы видим одновременно и отражение тоски по материнской родине, и восхищение природной аттрактивностью мест ссылки. Таким образом, происходит когнитивное разделение восприятия пространства у эстонцев, казалось бы, единого геополитического субъекта, то есть географические образы, в их понимании Замятина Д.Н. [5], разделяются на Сибирь и Россию.

Третье, что важно заметить: выход на первые роли памятных событий детей депортации запускает процесс детравматизации эстонского общества. П. Штомпка выделяет следующие фразы травматизации:

1) наличие культурной среды, способствующей возникновению травмы;

2) травматический инцидент;

3) поиск подходящих репрезентаций и создание травматического дискурса;

4) распространение травматических симптомов на то сообщество, которому они адресованы;

5) посттравматическая адаптация (институализация дискурса);

6) детравматизация - постепенное затухание симптомов травмы либо появление новой травмы, которая переключает внимание сообщества [17, c. 8].

Мы можем наблюдать все указанные этапы при интерпретации депортации эстонцев в 1949 г. как травмы, и указанные культурные акции символизируют адаптацию к аномии прошлого. В этом есть и влияние упомянутого лихуласского кризиса 2004 г. и последующей затем смены вектора культурной политики. Но детравматизация идёт не путём ретриатизма, то есть игнорирования травмы, попытки действовать, будто ее нет, а трансформации самого дискурса о нём. Это происходит не в полной мере, память о погибших родственниках, скончавшихся вследствие этих событий и осуждение действий советского правительства всё равно передаётся из уст в уста и отражается в искусстве, особенно в фольклоре депортантов.

Кроме того, само влияние окружающей среды на детские культурные травмы оказывает бальзамирующую роль. Особенность сибирского культурного ландшафрта в том, что здесь преобладает толерантность по отношению к переселенцам не только со стороны пришлого русского народа, но и со стороны местного населения. Несмотря на этническую пестроту проживающего населения, здесь не было крупных этнических конфликтов ни во времена присоединения сибирских территорий к Российской империи, ни во времена стремительного роста числа государств и самоопределения народов, ни в смутные для России 90-ые гг. и период распада Советского Союза [16, с. 303] 
(за исключением разве что длительной, но вялотекущей войны с енисейскими киргизами в XVII-XVIII вв. [10]). Неагрессивная для эстонцев среда сложилась на фоне памяти и даже текущей практики переселения русских в Сибирь, которое, начавшись в XVI в., продолжалось до советского времени, что выражалось в толерантности к ссыльным. Поэтому проживание в благоприятной среде сгладило эстонцам разлуку с родиной, а культурные ценности впитали в себя именно те, кто родились или проживали сознательное детство в Сибири.

\section{Заключение}

Проанализировав данную арт-программу, можно заключить, что смена поколений очевидцев памятных событий трансформирует и саму политику памяти и модернизирует картину мира общества. Так происходит влияние детского восприятия пространства на общественные и политические процессы. Обращение к детским впечатлениям является ключом к детравматизации общества, поскольку они носят ностальгический характер в силу психоэмоциональных особенностей восприятия своего личного опыта.

Даже несмотря на общий негативный фон национальной политики непосредственно к соседнему государству (в нашем случае это ассоциация России как правопреемницы Советского Союза), место родины, т. е. там, где человек провёл свой детство (в рассмотренном случае - Сибирь), как правило, воспринимается более позитивно. Таким образом, происходит двойственное эмоциональное восприятие России как геополитического субъекта эстонским обществом. Это выражается в устойчивых образах, ретранслированных в ходе мероприятий, таких как запах черёмухи, вкус иван-чая, фоотографиии и картины сибирских гор - эти механизмы отлично сработали не только для депортированных в то время, но и для последующих поколений.

Сибирь, в свою очередь, как социокультурное пространство обладает смягчающим воздействием культурной травмы насильственной депортации эстонцев в силу происхождения местного населения и исторических предпосылок, которое особенно впитывается во время становления детского мироощущения депортантов.

\section{Литература}

1. Аникин Д.А., Головашина О.В. Травмы культурной памяти: концептуальный анализ и методологические основания исследования // Вестник Томского государственного университета. 2017. № 425. С. 78-84.

2. Астров А. Эстония: политическая борьба за место в истории / А. Астров // Pro et contra. 2009. № 13. c. 109-125.

3. Горелова Г.В., Рябцев В.Н. Разработка когнитивных моделей геополитических систем (Черноморско-Каспийский регион) // Известия ЮФУ. Технические науки. 2014. № 6 (155). C. 22-32.

4. Дюков А.Р. Миф о генощиде: Репрессии советских властей в Эстонии (19401953) / Предисл. С. Артеменко. М.: Алексей Яковлев, 2007. 138 с.

5. Замятин Д.Н. Политико-географические образы и геополитические картины мира : представление географических знаний в моделях политического мышления // Политические исследования. 1998. № 6. С. 80-92.

6. Замятин Д.Н. Феноменология географических образов // Новое литературное обозрение. 2001. № 6. С. 13-15.

7. Замятин Д.Н. Метагеография: Пространство образов и образы пространства. М.: Аграф, 2004. 512 c.

8. Замятин Д.Н. Постгеография: капитал(изм) географических образов // Социологические исследования. 2014. № 10 (366). С. 3-14.

9. Колосов В. А. Критическая геополитика: основы концепции и опыт ее применения в России // Политическая наука. 2011. № 4. с. 31-52.

10. Кызласов Л.Р. О присоединении Хакасии к России. Сер. "страницы истории и современность". Вып. 2. Абакан : Изд-во Хакасского гос. ун-та им. Н.Ф. Катанова, 1996. $64 \mathrm{c}$.

11. Методологические вопросы изучения политики памяти: Сб. научн. тр. / Отв. ред. Миллер А. И., Ефременко Д. В. М. СПб: НесторИстория, 2018. 224 с.

12. Сафронова Ю.А. Историческая память: введение. СПб.: Изд-во Европейского университета в Санкт-Петербурге, 2019. 220 с. 
13. Рагулина М.В. Культурная география: теории, методы, региональный синтез /М. В. Рагулина; отв. ред. Б. М. Ишмуратов; Рос. акад. наук, Сиб. отд-ние, Ин-т географии. Иркутск, 2004. 171 с.

14. Рагулина М.В. Геополитика и географрия эмоций: проблема субъективности // Общество: политика, экономика, право. 2017. № 11. С. 28-31.

15. Титков А.С. Образы регионов в российском массовом сознании // Политические исследования. 1999. № 3. С. 61-75.

16. Фартышев А.Н. Геополитическое и геоэкономическое положение Сибири: моделирование и оценка // Вестник Санкт-Петербургского университета. Науки о Земле. 2017. T. 62 . № 3. C. 300-310.

17. Штомпка П. Социальное изменение как травма // Социологические исследования. 2001. № 1. С. 6-16.

18. Abakani vaksalist saab jälle Jõhvi raudteejaam Text: electronic. - Internet news program // Site Pohjarannik [Электронный pecypc]. URL: https:// pohjarannik. postimees.ee/6786522/abakani-vaksalist-saab-jalle-johvi-raudteejaam (дата обращения: 13.08.2020).

19. Kansteiner W. Finding Meaning in Memory. A Methodological Critique of Collective Memory Studies. // History and Theory. 2002. Vol. 41. No. 2. Pp. 179-197.

20. Kunstiprogramm "Siberi lapsepõlv. 70 aastat märtsiküüditamisest" üle Eesti 16 raudteejaamas Rühmitus SLED // Siberi Lapsed [Электронный pecypc]. URL: http://www.kultuurinfo.ee/syndmus/kunstiprogramm-siberi-lapsepolv-70-aastatmartsikuuditamisest/ (дата обращения: 13.08.2020).

21. Merton R.K. Social Structure and Anomie // American Sociological Review. 1938. Vol. 3. No. 5. Pp. 672-682.

\section{Транслитерация по ГОСТ 7.79-2000 Система Б}

1. Anikin D.A., Golovashina O.V. Travmy kul'turnoj pamyati: kontseptual'nyj analiz i metodologicheskie osnovaniya issledovaniya // Vestnik Tomskogo gosudarstvennogo universiteta. 2017. № 425. S. 78-84.

2. Astrov A. EHstoniya: politicheskaya bor'ba za mesto v istorii / A. Astrov // Pro et contra. 2009. № 13. s. 109-125.

3. Gorelova G.V., Ryabtsev V.N. Razrabotka kognitivnykh modelej geopoliticheskikh sistem (CHernomorsko-Kaspijskij region) // Izvestiya YUFU. Tekhnicheskie nauki. 2014. № 6 (155). S. 22-32.

4. Dyukov A.R. Mif o genotside: Repressii sovetskikh vlastej v EHstonii (1940-1953) / Predisl. S. Artemenko. M.: Aleksej YAkovlev, 2007. 138 s.

5. Zamyatin D.N. Politiko-geograficheskie obrazy i geopoliticheskie kartiny mira : predstavlenie geograficheskikh znanij v modelyakh politicheskogo myshleniya // Politicheskie issledovaniya. 1998. № 6. S. 80-92.

6. Zamyatin D.N. Fenomenologiya geograficheskikh obrazov // Novoe literaturnoe obozrenie. 2001. № 6. S. 13-15.

7. Zamyatin D.N. Metageografiya: Prostranstvo obrazov i obrazy prostranstva. M.: Agraf, 2004. 512 s.

8. Zamyatin D.N. Postgeografiya: kapital(izm) geograficheskikh obrazov // Sotsiologicheskie issledovaniya. 2014. № 10 (366). S. 3-14.

9. Kolosov V. A. Kriticheskaya geopolitika: osnovy kontseptsii i opyt ee primeneniya v Rossii // Politicheskaya nauka. 2011. № 4. s. 31-52.

10. Kyzlasov L.R. O prisoedinenii KHakasii k Rossii. Ser. "stranitsy istorii i sovremennost"'. Vyp. 2. Abakan : Izd-vo KHakasskogo gos. un-ta im. N.F. Katanova, 1996. 64 s.

11. Metodologicheskie voprosy izucheniya politiki pamyati: Sb. nauchn. tr. / Otv. red. Miller A. I., Efremenko D. V. M. SPb: NestorIstoriya, 2018. 224 s.

12. Safronova YU.A. Istoricheskaya pamyat': vvedenie. SPb.: Izd-vo Evropejskogo universiteta v Sankt-Peterburge, 2019.220 s.

13. Ragulina M.V. Kul'turnaya geografiya: teorii, metody, regional'nyj sintez /M. V. Ragulina; otv. red. B. M. Ishmuratov; Ros. akad. nauk, Sib. otd-nie, In-t geografii. Irkutsk, 2004. 171 s.

14. Ragulina M.V. Geopolitika i geografiya ehmotsij: problema sub"ektivnosti // Obshhestvo: politika, ehkonomika, pravo. 2017. № 11. S. 28-31.

15. Titkov A.S. Obrazy regionov v rossijskom massovom soznanii // Politicheskie issledovaniya. 1999. № 3. S. 61-75.

16. Fartyshev A.N. Geopoliticheskoe i geoehkonomicheskoe polozhenie Sibiri: modelirovanie i otsenka // Vestnik Sankt-Peterburgskogo universiteta. Nauki o Zemle. 2017. T. 62. № 3. S. 300-310.

17. SHtompka P. Sotsial'noe izmenenie kak travma // Sotsiologicheskie issledovaniya. 2001. № 1. S. 6-16.

18. Abakani vaksalist saab jälle Jõhvi raudteejaam Text: electronic. - Internet news program // Site Pohjarannik [Ehlektronnyj resurs]. URL: https:// pohjarannik.pos- 
timees.ee/6786522/abakani-vaksalist-saab-jalle-johvi-raudteejaam (data obrashheniya: 13.08.2020).

19. Kansteiner W. Finding Meaning in Memory. A Methodological Critique of Collective Memory Studies. // History and Theory. 2002. Vol. 41. No. 2. Rp. 179-197.

20. Kunstiprogramm "Siberi lapsepõlv. 70 aastat märtsiküüditamisest" üle Eesti 16 raudteejaamas Rühmitus SLED // Siberi Lapsed [Ehlektronnyj resurs]. URL: http://www. kultuurinfo.ee/syndmus/kunstiprogramm-siberi-lapsepolv-70-aastat-martsikuuditamisest/ (data obrashheniya: 13.08.2020).

21. Merton R.K. Social Structure and Anomie // American Sociological Review. 1938. Vol. 3. No. 5. Rp. 672-682..

Фартышев А. Н., Раева Д. Д. Детство в Сибири: восприятие пространства әстонцами, пережившими советскую депортацию.

В статье проведён анализ арт-программы "Детство в Сибири", проходившей в Эстонии в 2019 г., посвящённой памяти депортации соотечественников вследствие советской операции "Прибой" 1949 г. Основными субъектами этой программы выступили люди, которые родились, либо провели детство в Сибири. Выявлено, что, несмотря на общий негативный фон по отношению к Советскому Союзу и России, эстонцы совершенно иначе воспринимают Сибирь, которая стала для них второй родиной. Таким образом, возникает дуалистическое эмоциональное восприятие геополитического пространства России и его составных частей. Картина мира эстонских депортантов, сформированная в детстве, запускает процессы мирной детравматизации прошлого, благодаря толерантности сибиряков к ссыльным эстонцам.

Ключевые слова: политика паляти, тетоry studies, культурная политика, эстонская политика, география образов, критическая геополитика, культурная география, культурная травма, ментальная географби, метагеографбл

Fartyshev A. N., Raeva D. D. Childhood in Siberia: the perception of space by Estonians, survived the Soviet deportation.

The article provides a analysis of the content of the art program "Childhood in Siberia", held in Estonia in 2019, dedicated to the memory of the deportation of compatriots as a result of the Soviet operation "Surf" in 1949. The main subjects of this program were people who were born or spent their childhood in Siberia. It was revealed that, despite the general negative background in relation to the Soviet Union and Russia, Estonians perceive Siberia in a completely different way, which has become their second homeland. Thus, a dualistic emotional perception of Russia's geopolitical space arises. The picture of the world of Estonian deportants, formed in childhood, triggers the processes of peaceful detraumatization of the past, due to the tolerance of Siberians to exiled Estonians.

Key words: politics of memory, memory studies, cultural politics, Estonian politics, geography of images, critical geopolitics, cultural geography, cultural trauma, mental geography, metageography

Для цитирования: Фартышев А. Н., Раева Д. Д. Детство в Сибири: восприятие пространства эстонцами, пережившими советскую депортацию // Ойкумена. Регионоведческие исследования. 2021. № 2. С. 67-73. DOI: 10.24866/1998-6785/2021-2/67-73

For citation: Fartyshev A. N., Raeva D. D. Childhood in Siberia: the perception of space by Estonians, survived the Soviet deportation // Ojkumena. Regional researches. 2021. № 2. P. 67-73. DOI: $10.24866 / 1998-6785 / 2021-2 / 67-73$ 